Defining the qualitative elements of

Aichi Biodiversity Target 11 with regard

to the marine and coastal environment

in order to strengthen global efforts for

marine biodiversity conservation

outlined in the United Nations

\title{
Sustainable Development Goal 14
}

Rees, Sian

http://hdl.handle.net/10026.1/9458

10.1016/j.marpol.2017.05.016

Marine Policy

Elsevier BV

All content in PEARL is protected by copyright law. Author manuscripts are made available in accordance with publisher policies. Please cite only the published version using the details provided on the item record or document. In the absence of an open licence (e.g. Creative Commons), permissions for further reuse of content should be sought from the publisher or author. 


\title{
Defining the qualitative elements of Aichi Biodiversity Target 11 with regard to the marine and coastal environment in order to strengthen global efforts for marine biodiversity conservation outlined in the United Nations Sustainable Development Goal 14
}

\author{
Siân E. Rees ${ }^{\mathrm{a}, *}$, Nicola L. Foster ${ }^{\mathrm{a}}$, Olivia Langmead ${ }^{\mathrm{a}, \mathrm{b}}$, Simon Pittman ${ }^{\mathrm{a}, \mathrm{c}}$, David E. Johnson ${ }^{\mathrm{d}}$ \\ a Marine Institute, 3rd Floor Marine Building, Plymouth University, Plymouth PL4 8AA, UK \\ b Marine Biological Association of the United Kingdom, the Laboratory, Citadel Hill, Plymouth PL1 2PB, UK \\ c National Oceanic and Atmospheric Administration, National Centers for Coastal Ocean Science Center for Coastal Monitoring \& Assessment, Biogeography Branch \\ SSMC4, 1305 East-West Highway, Silver Spring, MD 20910, United States \\ d Global Ocean Biodiversity Initiative Programme Coordinator, Seascape Consultants Ltd, Belbins Valley, Romsey SO51 OPE, UK
}

\section{A R T I C L E I N F O}

\section{Keywords:}

Convention on Biological Diversity

Marine Protected Areas

Management effectiveness

Ecosystem services

Ecological coherence

Ecologically representative

Connected

Marine spatial planning

EBSAs

\begin{abstract}
A B S T R A C T
The Convention on Biological Diversity (CBD) Aichi Target 11 states that, "by 2020, at least 17 per cent of terrestrial and inland water, and 10 per cent of coastal and marine areas, especially areas of particular importance for biodiversity and ecosystem services, are conserved through effectively and equitably managed, ecologically representative and well-connected systems of protected areas and other effective area-based conservation measures, and integrated into the wider landscapes and seascapes". There has been rapid progress to meet the quantitative goal (the $10 \%$ target). However, the qualitative aspects of Aichi target 11 are less well described. The United Nations Sustainable Development Goal (SDG) 14 to "conserve and sustainably use the oceans, seas and marine resources for sustainable development" reaffirms the quantitative element of Aichi target 11, and, through the described sub-targets, places further emphasis on the economic and social context of global development. The complexity of the language from Aichi target 11 is not mirrored in SDG 14, leading to a potential scenario where the knowledge and progress towards Aichi Target 11 will be diluted as the focus shifts to the SDGs. This paper presents current knowledge and implementation of the qualitative elements of Aichi Target 11 and highlights gaps in knowledge. We conclude that the progress made so far on describing and implementing the qualitative goals of Aichi Target 11 should be integrated into SDG 14 in order to strengthen global efforts for marine biodiversity conservation and support the broader vision for sustainable development that will "transform our world".
\end{abstract}

\section{Introduction}

The term "protected area" is described in Article 2 of the Convention on Biological Diversity (CBD) as "a geographically defined area, which is designated or regulated and managed to achieve specific conservation objectives" [1]. In 2004, the CBD Conference of Parties (COP) agreed that "marine and coastal protected areas are an essential tools and approaches in the conservation and sustainable use of marine and coastal biodiversity", committing to a target of "effective conservation of at least $10 \%$ of each of the world's ecological regions by 2010 " (UNEP/CBD/COP/DEC/VII/5). CBD Parties also agreed that a national framework of marine and coastal protected areas should include a range of levels of protection, encompassing both areas that allow sustainable uses and those that prohibit extractive uses (i.e., "no-take" areas)" (UNEP/CBD/COP/DEC/VII/5). The "goals and global outcome targets" for marine and coastal biodiversity were further endorsed by COP in 2006 (UNEP/CBD/COP/ DEC/VIII/15).

In 2010, CBD Parties agreed to extend the deadline for reaching the target of conserving $10 \%$ of their marine and coastal regions in protected areas from 2012 to 2020 (UNEP/CBD/COP/10/27). They also adopted a revised and updated Strategic Plan for Biodiversity 2011-2020. The Plan set out 20 Aichi Biodiversity Targets, organised under five strategic goals that seek to ensure that "By 2050, biodiversity is valued, conserved, restored and wisely used, maintaining ecosystem services, sustaining a healthy planet and delivering benefits essential for all people" (UNEP/CBD/COP/10/27/Annex). Aichi Target 11 is

\footnotetext{
* Corresponding author.

E-mail address: sian.rees@plymouth.ac.uk (S.E. Rees).
} 
Table 1

The quantitative targets and qualitative elements that define how Aichi target 11 may be achieved.

Source:Adapted from Jonas and Lucas [2].

\begin{tabular}{|c|c|}
\hline Quantitative targets & $\begin{array}{l}17 \% \text { terrestrial } \\
10 \% \text { coastal and marine }\end{array}$ \\
\hline Means of conservation & $\begin{array}{l}\text { Protected areas } \\
\text { Other effective area-based conservation measures }\end{array}$ \\
\hline Qualitative elements & $\begin{array}{l}\text { Ecologically representative } \\
\text { Areas of particular importance for biodiversity and } \\
\text { ecosystem services } \\
\text { Management equity and effectiveness } \\
\text { Well-connected } \\
\text { Integration into wider landscape and seascape }\end{array}$ \\
\hline
\end{tabular}

within Strategic Goal C: To improve the status of biodiversity by safeguarding ecosystems, species and genetic diversity. Aichi Target 11 specifically states that, "by 2020 , at least 17 per cent of terrestrial and inland water, and 10 per cent of coastal and marine areas, especially areas of particular importance for biodiversity and ecosystem services, are conserved through effectively and equitably managed, ecologically representative and well-connected systems of protected areas and other effective area-based conservation measures, and integrated into the wider landscapes and seascapes" (UNEP/CBD/COP/10/27/Annex). The text comprises both quantitative targets and qualitative elements that define how Aichi Target 11 may be achieved (Table 1).

In 2012 CBD Parties were invited to undertake major efforts to achieve all elements of Aichi Biodiversity Target 11 (UNEP/CBD/COP/ DEC/XI/24). The Fourth Global Biodiversity Outlook in 2014 reported varying levels of progress for the different elements of Aichi Target 11 and this was subsequently updated in a report to the CBD Subsidiary Body on Technical and Technological Advice (UNEP/CBD/SBSTTA/20/ $\mathrm{INF} / 43$ ) in 2016. In terms of the quantitative targets there has been rapid progress in the global drive to meet the goal for the $10 \%$ area coverage of coastal and marine areas via the designation of Marine Protected Areas (MPAs). The MPAtlas reports that $2.07 \%$ of the global ocean is within an MPA, with $5.27 \%$ in national jurisdictions [3]. Proposed MPAs will add a further $3.62 \%$ of the global ocean as MPAs, with an additional $7.71 \%$ of MPAs designated within national jurisdictions [3]. CBD reporting draws on the Protected Planet Report [4] claiming coverage of $10.9 \%$ in coastal waters ( $0-12$ nautical miles) and $8.4 \%$ in areas within national jurisdiction or the Exclusive Economic Zone (0-200 nautical miles).

There is also increasing attention on the practical interpretation of "other effective area-based conservation measures" (OECM) as a "means of conservation". The IUCN Task Force on Other Effective Area based Conservation measures has defined OECMs as "a geographical space where de-facto conservation of nature and associated ecosystem services and cultural values is achieved and expected to be maintained in the long term regardless of specific recognition and dedication" [5]. The identification of OECMs that can contribute to ecologically representative and well-connected MPA networks and progress toward the $10 \%$ spatial target, is a key challenge [4]. The recently published WCPA report, "Advancing guidance on other effective area-based conservation measures" introduces a "screening tool" for the identification of an OECM [6].

The qualitative aspects of Aichi target 11 are, at present, less well described. Essentially they broaden the scope of the quantitative target in support of the ecological premise that there is a high level of functional and spatial connectivity within marine ecosystems [7-10] and that area-based targets alone may not be adequate to safeguard the important ecosystem processes and services that marine ecosystems underpin [11]. These qualitative elements of Aichi Target 11 form a more holistic perspective of MPA design and function by considering contextual setting and also provide the means to be systematic in an approach to planning for marine biodiversity conservation [12]. They also support the principles of "ecological coherence" [13,14], whereby a "network of MPAs" (a collection of individual MPAs or reserves operating cooperatively and synergistically, at various spatial scales) is designed to.

- Interact and support the wider environment [15, Sections 5.3 and 6];

- Maintain the processes, functions, and structures of the intended protected features across their natural range [13];

- Function synergistically as a whole, such that the individual protected sites benefit from each other to achieve the above two objectives [15];

- Additionally, an ecologically coherent network of MPAs may be designed to be resilient to changing conditions [15, Section 5].

The recently defined Sustainable Development Goals (SDGs) were adopted in 2015 by the 193 members of the United Nations General Assembly as the reference goals for the international development community for the period 2015-2030 [16]. They demonstrate twin priorities of protection of the Earth life-support system with poverty reduction. The SDGs advocate a "triple bottom line" approach to maintaining human wellbeing; these being economic development, environmental sustainability and social inclusion [17]. SDG 14 to "conserve and sustainably use the oceans, seas and marine resources for sustainable development" is directly relevant to Aichi Target 11. Essentially, SDG 14 reaffirms the Aichi Target 11 (to conserve at least 10 per cent of coastal and marine areas (SDG sub-target 14.5)), and, more broadly, places greater emphasis on the economic and social context of conservation measures to aid global development. SGD 14 does not, however, mirror the detail and ambition of Aichi Target 11. It simply echoes the target for the spatial extent of MPAs (10\%) and gives no direction on what is being protected or how that protection may be achieved [18]. It is considered that conservation targets that focus solely on spatial extent exclude aspects of ecological coherence and do not confer any means of indication of positive or negative biodiversity outcomes [11,19]. This lack of ambition within the language of SDG 14 is notable as, despite great achievements in increasing the spatial extent of MPAs [20], it is well recorded that the continued degradation and loss of marine species and population decline are critically impairing the ability of marine systems to continue to provide ecosystem services that underpin human wellbeing [21-26]. There are notable synergies between the conservation of marine biodiversity and the broader remit of the SDGs particularly with regard to Goal 1: End poverty in all its forms everywhere; Goal 13: Take urgent action to combat climate change and its impacts. It considered here though that the integration of Aichi target 11 into SDG 14, in particular, could strengthen global efforts for marine biodiversity conservation. To this end, this paper presents current progress on the interpretation of the qualitative elements of Aichi Target 11 with regard to the marine and coastal environment; presents alignment between SDG 14 and the qualitative elements of Aichi Target 11 and; highlights gaps in knowledge in the current implementation of the qualitative elements of Aichi Target 11 in order to facilitate the integration with SDG 14.

\section{Ecologically representative}

To be ecologically representative, the full range of ecosystems, habitats, biotic diversity, ecological processes, and environmental gradients (e.g. depth, wave exposure) need to be included within the MPA network [15,27-30]. In 2008 CBD Parties further defined "scientific guidance for selecting areas to establish a representative network of MPAs, including in open ocean waters and deep sea habitats" (UNEP/CBD/COP/DEC/IX/20/Annex II). A "representative" network comprises of the following properties and components: Ecologically or Biologically Significant Marine Areas (EBSAs); Repre- 
sentativity; Connectivity; Replicated Ecological Features; Adequate and viable sites. (UNEP/CBD/COP/DEC/IX/20/Annex II). CBD Parties defined representativity as being "captured in a network when it consists of areas representing the different biogeographical subdivisions of the global oceans and regional seas that reasonably reflect the full range of ecosystems, including the biotic and habitat diversity of these marine ecosystems" (UNEP/CBD/COP/DEC/IX/20/Annex II). Furthermore, CBD Parties recognised that ecological representation "refers to the need for protected areas to represent, or sample, the full variety of biodiversity for the different biological realms, in all eco-regions (freshwater, marine and terrestrial), and the different biological scales (ecosystems, species and within species variations)" (UNEP/CBD/SBSTTA/20/INF/43, 24, p.11).

The objective in applying this criterion to marine biodiversity conservation is to ensure representative coverage of biodiversity and biogeographic regions [27,31]. Spatially, of the 13,647 MPAs designated globally there is a greater proportion of MPAs in waters within national jurisdictions $(0-200 \mathrm{~nm})$ than in areas beyond national jurisdiction [3]. In terms of the distribution of MPAs in areas within national jurisdictions it can be observed that existing MPAs are focused in the intertidal and nearshore areas [18]. To support ecological representativity within the coastal environment, Woodley et al. [32] recommended that the CBD 10\% area protection threshold under Aichi Target 11 be altered to designate " $10 \%$ of each coastal marine ecoregion as protected areas by 2020 " to ensure greater ecological representativity in the overall $10 \%$ spatial target.

Sub-regional assessments for parameters of ecological representativity of MPA designations in North America [33]; the UK ([34,35]; Northern Ireland [36]; the Celtic Seas [37,38]; the OSPAR region [39,40]; The English Channel [35]; the Baltic [41] and the NE Atlantic [42], demonstrate that whilst progress is being made towards the $10 \%$ protected area spatial target the existing MPAs are not truly representative of the full range of ecosystems and are therefore not currently ecologically representative. In Australia, however, an initiative to address gaps in representativity in the zoning plan for the Great Barrier Reef Marine Park was developed using local expert knowledge coordinated through the Representative Areas Programme for the Great Barrier Reef Marine Park Authority. The process revealed that the original zoning plan was unlikely to adequately protect the entire range of biodiversity in the region and progressed to define a new set of biophysical operational principles resulting in 33\% of the Marine Park being no-take encompassing at least $20 \%$ of each of the 70 bioregions [43].

Biogeographic classifications, that map patterns of biodiversity into distinct realms, provinces and ecoregions, provide a spatial reference to support conservation planning that span coastal and offshore ecosystems $[44,45]$. In a recent review of the global biogeographic coverage of MPAs, Butchart et al. [46] demonstrate that the most well represented (within MPA) biogeographic region is the tropical coastal realm (with the exception of the Western Indo Pacific). Temperate and polar realms are underrepresented in MPAs (except in Australia and the North Atlantic [18,46]).

"Ecologically representative" has also been interpreted by using methods to identify whether habitats and species of conservation importance are "represented" within MPAs and replicated against agreed thresholds to ensure natural variation and to minimise the effects of damaging events and long-term change (resilience) [29,47]. Replication of habitats and species within MPAs in the network is considered to be good practice in MPA network design and helps to spread the risk should a catastrophic event occur. This method is employed as a presence/absence exercise based on species listed for conservation within official documents e.g. MPA management plans [48]. This method does not however consider the absolute area of the habitats (or the size of populations) enclosed in the MPAs, or the proportion of the overall occurrence of the habitat to come under an MPA management scheme $[49,50]$. A global assessment of the ecolo- gical representativeness of biodiversity within MPAs by Butchart [46] assessed the presence of 400 marine species by applying parameters for the minimum proportion of the "range" required to ensure the long term sustainability. Whilst several species of bony fish and stony corals were located in MPAs within their "range" there is no information on the management measures for the species across their "range" and therefore no inference can be made about whether MPAs support long term sustainability of the species nor if the network is truly representative.

Methods to assess ecological representativity of protected areas networks at various scales are advancing. Based on the scientific guidance for a representative network of MPAs (UNEP/CBD/COP/ $\mathrm{DEC} / \mathrm{IX} / 20 /$ Annex II) there is an obvious need to re-examine the required network properties and components for an "ecologically representative" network and move beyond criteria for "representativity" to consider how rare and unique habitats defined in the EBSA process may contribute to an ecologically coherent network of MPAs.

Furthering the application of these methods under SDG 14 must be based on the simple underlying premise that to spread the risk spatially across the seascape by representing and replicating the full range of ecosystem types and components is a basic prerequisite for the protection of the range of marine biodiversity [51-53]. An ecologically representative system of protected areas directly supports the motives of SDG 14.2 (Table 2) as sustainable management and risk management are closely aligned. Sustainable management requires that parameters linked to risk and uncertainties are identified and evaluated (e.g. Risk Assessments). Additionally SGD 14.1 (marine pollution) and 14.3 (ocean acidification) are also supported by an ecologically representative system of protected areas (Table 2) as efforts to underpin the resilience of ecosystems through representivity reduces the risk of regime shifts, where an ecosystem shifts from a desired state to a less desired state due to either a catastrophic event e.g. a pollution event or the effect of long term stressors e.g. climate change [54]. As regime shifts also impact upon the realisation or delivery of ecosystem services that support human wellbeing [54] SGD 14.7 (economic benefits) is also underpinned by an ecologically representative system of protected areas (Table 2). There are potential synergies here with SDG Goal 13 to "strengthen resilience and adaptive capacity to climate-related hazards and natural disasters in all countries". Resilience is also a central component of Goal 1 build the resilience of the poor and those in vulnerable situations and reduce their exposure and vulnerability to climate-related extreme events and other economic, social and environmental shocks and disasters.

To integrate "Ecologically Representative" into SDG14 there is a need to address the key challenges faced by countries at national or regional levels in the incorporation of "ecological representativity in conservation planning (e.g. data needs, capacity etc.). At a global level there is a need to improve understanding of marine biogeography in support of ecological representativity, particularly for Areas Beyond National Jurisdiction (ABNJ) [55]. Also, to decide what functions representativity should deliver (e.g. propagule stock function, ensuring the potential for restoration). In light of the recent trend in the designation of large MPAs there is also a need to understand how and if these sites contribute to ecological representativity.

\section{Well-connected}

Connectivity describes the extent to which populations in different parts of a species' range are linked by the exchange of larvae, recruits, juveniles or adults [56]. Connectivity forms a vital component of metapopulation and landscape ecology, influencing a number of fundamental processes, including population dynamics, evolution and community responses to climate change $[57,58]$. For well-connected systems of protected areas, the CBD consider landscape connectivity as the degree to which the landscape facilitates or impedes movement among patches. In the context of protected areas "movement can be 
facilitated by a number of mechanisms, including conservation corridors, transboundary corridors, stepping stones, regional connectivity corridors, and ecoregion conservation programmes such as those forwarded by organisations such as WWF and Conservation International" (UNEP/CBD/SBSTTA/20/INF/43, §61, p.19). In the marine realm, the CBD described connectivity in the design of a network as allowing "for linkages whereby protected sites benefit from larval and/ or species exchanges, and functional linkages from other network sites. In a connected network individual sites benefit one another" UNEP/ CBD/COP/DEC/IX/20/Annex II. Such sites that may improve the connectivity of a network include currents, gyres, physical bottlenecks, migration routes, species dispersal, detritus, functional linkages and seamount communities UNEP/CBD/COP/DEC/IX/20/Annex II.

Understanding the extent to which populations and sites are connected is critical both for the design of MPA networks to protect biodiversity and for the development of conservation strategies to protect species associated with degrading and fragmenting habitats $[28,59,60]$. There has been significant progress in the methods used to assess connectivity in recent decades; however, connectivity varies greatly depending on the abundance and density of individuals, species and habitat characteristics, and the temporal and spatial scale of studies [57], which poses challenges in terms of its assessment and its use in reserve design and management. Connectivity can be assessed in a number of ways, including direct and indirect studies of larval, juvenile, and adult movements using tracking, mark and recapture, chemical markers or genetic techniques $[57,61]$. An alternative to such empirical studies is a biophysical modelling approach based on distance between habitat patches, the hydrodynamics of the surrounding area and the behavior of individuals within the populations, which provides an estimate of potential connectivity which may differ from actual connectivity $[57,62]$.

Assessing connectivity of populations within MPA networks is often overlooked or completed on a very coarse scale due to data constraints and the limited timeframe and financial restrictions placed on such assessments. MPA networks typically cover broad spatial scales (100's kilometres) and incorporate the habitat for a diverse range of species and biological communities. Larval dispersal and movement of individuals varies significantly between species, yet most connectivity studies undertaken in relation to management focus on only one or a small number of species [62], or are based on a buffer distance between habitats or even MPA sites, with minimal ecological relevance or consideration of the distances typically moved by various species during different life history stages $[63,64]$. While conservation planning software that includes aspects of connectivity is available, these are not always appropriate for retrospective assessments of MPA networks that are already established. Including accurate connectivity measures in MPA network assessments requires an understanding of the needs of multiple species and habitats, habitat quality and connectivity, population dynamics and short-term and long-term objectives [57,62]. Thus, more accurate and comprehensive assessments of connectivity within MPA networks has been identified as a research requirement to establish MPA network effectiveness both in terms of recovery process inside MPAs and connectivity among MPAs [65].

Quantifying connectivity will require greater financial and time investment to undertake detailed biophysical modelling or empirical studies of the connectivity of a number of species within the network that could represent the life history strategies of a range of species. For example, modelling the connectivity of a number of key species that include sessile, low mobility and high mobility species, and those with and without or with long and short planktonic larval stages would go some way to improving connectivity assessments. Recent technological advances mean that this is no longer inconceivable; however, such detailed assessments need to be balanced against the time-constraints of conservation planning and MPA network assessments. In many situa-

Table 2

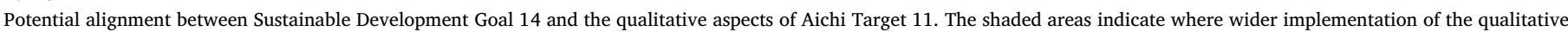
aspects of Aichi target 11 would support the vision of SDG 14 based on the literature presented in this paper.

\begin{tabular}{|c|c|c|c|c|c|c|c|}
\hline & & & \multicolumn{5}{|c|}{ Qualitative aspects of Aichi target 11} \\
\hline & & & 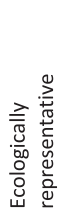 & 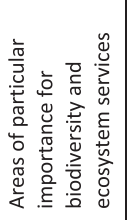 & 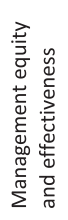 & 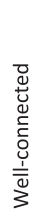 & 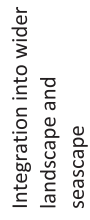 \\
\hline \multirow{10}{*}{ 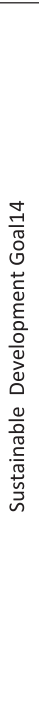 } & 14.1 & $\begin{array}{l}\text { By 2025, prevent and significantly reduce marine pollution of all kinds, in particular from land-based activities, including } \\
\text { marine debris and nutrient pollution. }\end{array}$ & & & & & \\
\hline & 14.2 & $\begin{array}{l}\text { By } 2020 \text {, sustainably manage and protect marine and coastal ecosystems to avoid significant adverse impacts, including } \\
\text { by strengthening their resilience, and take action for their restoration in order to achieve healthy and productive } \\
\text { oceans. }\end{array}$ & & & & & \\
\hline & 14.3 & Minimize and address the impacts of ocean acidification, including through enhanced scientific cooperation at all levels. & & & & & \\
\hline & 14.4 & $\begin{array}{l}\text { By 2020, effectively regulate harvesting and end overfishing, illegal, unreported and unregulated fishing and destructive } \\
\text { fishing practices and implement science-based management plans, in order to restore fish stocks in the shortest time } \\
\text { feasible, at least to levels that can produce maximum sustainable yield as determined by their biological characteristics. }\end{array}$ & & & & & \\
\hline & 14.5 & $\begin{array}{l}\text { By 2020, conserve at least } 10 \text { per cent of coastal and marine areas, consistent with national and international law and } \\
\text { based on the best available scientific information. }\end{array}$ & \multicolumn{5}{|c|}{ Same as the quantitative target in Aichi Target 11} \\
\hline & 14.6 & $\begin{array}{l}\text { By 2020, prohibit certain forms of fisheries subsidies which contribute to overcapacity and overfishing, eliminate } \\
\text { subsidies that contribute to illegal, unreported and unregulated fishing and refrain from introducing new such } \\
\text { subsidies, recognizing that appropriate and effective special and differential treatment for developing and least } \\
\text { developed countries should be an integral part of the World Trade Organization fisheries subsidies negotiation. }\end{array}$ & & & & & \\
\hline & 14.7 & $\begin{array}{l}\text { By } 2030 \text {, increase the economic benefits to Small Island developing States and least developed countries from the } \\
\text { sustainable use of marine resources, including through sustainable management of fisheries, aquaculture and tourism. }\end{array}$ & & & & & \\
\hline & $14 a$ & $\begin{array}{l}\text { Increase scientific knowledge, develop research capacity and transfer marine technology, taking into account the } \\
\text { Intergovernmental Oceanographic Commission Criteria and Guidelines on the Transfer of Marine Technology, in order } \\
\text { to improve ocean health and to enhance the contribution of marine biodiversity to the development of developing } \\
\text { countries, in particular small island developing States and least developed countries. }\end{array}$ & & & & & \\
\hline & $14 \mathrm{~b}$ & Provide access for small-scale artisanal fishers to marine resources and markets. & & & & & \\
\hline & $14 \mathrm{c}$ & $\begin{array}{l}\text { Enhance the conservation and sustainable use of oceans and their resources by implementing international law as } \\
\text { reflected in UNCLOS, which provides the legal framework for the conservation and sustainable use of oceans and their } \\
\text { resources, as recalled in paragraph } 158 \text { of The Future We Want. }\end{array}$ & & & & & \\
\hline
\end{tabular}


tions, implementation of certain management actions may be too urgent to wait for comprehensive knowledge on the connectivity of a wide range of species [66].

Like "ecologically representative" a "well-connected" system of protected areas is a prerequisite for biodiversity conservation. Connectivity forms a central tenant of "ecological coherence", where a network of MPAs is designed to interact and support the wider environment in order to underpin the resilience of the ecological system (SDG 14.2 and 14.3) (Table 2). Through resilience, the risk of permanent loss of ecosystem functions and ecosystem service benefits is reduced thus supporting SDG 14.7 (Table 2). "Well-connected" must therefore become integral to SDG 14.5 and the 10\% target. Significant progress has been made in both empirical and modelling studies of connectivity in the past decade; however, challenges remain in understanding how best to include connectivity in conservation management $[57,67]$. These include how to define minimum and optimal information needs for an assessment of connectivity to inform network design and management when considering a diverse set of phyla, families and species with many different modes and domains of dispersal. There is additionally an issue of scale; at what scale should connectivity be assessed in order for the assessment to be meaningful for MPA managers and planners?

\section{Areas of particular importance for biodiversity and ecosystem services}

From the text of the CBD, "Biological diversity means the variability among living organisms from all sources, including inter alia, terrestrial, marine and other aquatic ecosystems and the ecological complexes of which they are part; this includes diversity within species, between species and of ecosystems" [68]. The Millennium Ecosystem Assessment (MEA) established the concept of ecosystem services on the global agenda as "the benefits people obtain from ecosystems" [23] and although ecosystem services are defined in a variety of ways [69-71] the common theme is the translation of ecosystem functions and processes into direct or indirect benefits for human wellbeing [72]. In the progress towards implementation of "areas of particular importance for biodiversity and ecosystem services," the process to achieve implementation of this has focussed largely on "areas of particular importance for biodiversity" with methods and tools rapidly being developed to identify "areas important for ecosystem services".

\subsection{Areas of particular importance for biodiversity}

The protection of biodiversity has historically taken precedent in conservation planning in so far that it forms a central component of MPA network planning through the generation of lists to identify and protect habitats and species considered to be important at various scales, e.g. The European Union (EU) Habitats Directive list of Annex I habitats and Annex II species 92/43/EEC, which form the backbone of the EU Natura 2000 protected area network. It can be considered that where these habitats and species have been identified in situ, that these are considered as being important areas for biodiversity in regional planning systems.

The CBD Secretariat noted that "areas of particular importance for biodiversity or Key Biodiversity Areas (KBAs) are areas that are locally, nationally and globally important for the manifestation of biodiversity at the genetic, species and/or ecosystem level; they are identified using global criteria and thresholds. Different areas important for biodiversity are important bird and biodiversity areas (IBAs), Alliance for Zero Extinction sites (AZEs), Biodiversity Hotspots, high biodiversity wilderness and global 200 priority ecoregions" (UNEP/CBD/SBSTTA/20/ INF/43, §32, p.13).

At the global scale in 2008 CBD Parties approved scientific criteria for the identification of Ecologically or Biologically Significant Marine Areas (EBSAs) (UNEP/CBD/COP/9/29/DEC/IX/20). In 2010, CBD
Parties established a science-led process for the description of EBSAs across the world's oceans against the agreed criteria (UNEP/CBD/COP/ DEC/X29) [73]. The purpose of the description of EBSA is to inform States and competent intergovernmental organisations that have a responsibility to take measures to protect important areas for ecological functioning, so future planning can take into account the need for the integrated management of resource-use and conservation [74]. EBSA information can also be used by national and sub-national governments, and to inform research planning. There are currently 279 EBSAs described by CBD Parties following a series of twelve regional EBSA Workshops. These EBSAs encompass 19\% of the world's oceans including coastal areas, continental shelf areas and ABNJ. The EBSA information has been placed in the CBD EBSA Repository and Information Sharing Mechanism and details have been conveyed to the United Nations General Assembly and other competent bodies. It is important to note here that EBSAs, KBAs, IBAs, AZEs, Biodiversity Hotspots, high biodiversity wilderness and global 200 priority ecoregions are not MPA designations though in several instances boundaries may overlap. Therefore, these areas are not currently considered as part of the $10 \%$ spatial protection target nor are they currently considered in assessments of ecological coherence of MPA networks.

\subsection{Areas important for ecosystem services}

The MEA identified four categories of ecosystem services: Provisioning services that supply material resources; regulating services that control ecological systems; cultural services that provide nonmaterial aesthetic, spiritual and recreational benefits; and supporting services that provide the basic ecological functions and structures that underpin all other services, such as primary production, biodiversity, oxygen production, soil formation and nutrient cycling [23]. The Economics of Ecosystems and Biodiversity (TEEB) project builds upon the MEA classification, distinguishing between the core ecosystem processes that support beneficial ecosystem processes, which in turn deliver beneficial ecosystem services in the form of material or nonmaterial benefits for human well-being [71]. The biophysical structures and processes provide the prerequisites for ecosystem functions, which in turn have the potential to deliver services that contribute to human well-being and as such have a value to humans. Nutrient cycling (process), for example, is a prerequisite for water purification (function) to provide freshwater (provisioning service), which is essential for human health (benefit) [75]. Economic or non-economic/qualitative valuation techniques can be applied to realise a value for freshwater, which ascribes a value to the ecosystem services.

In the broadest sense, areas that are "important for biodiversity" (whether this includes areas that are species-rich, functionally diverse or are important for an iconic aspect of biodiversity) and areas that are important for ecosystem services are linked. For example, by effectively managing and conserving areas that are recognised as being important for ecological functions (e.g. EBSAs), there is the potential for underpinning those beneficial ecosystem services that contribute to human well-being. If an iconic species is protected via management measures e.g. whale sharks, then recreation/tourism benefits can be realised as the final ecosystem service. The literature has a wide range of different and evolving interpretations of what constitutes as an ecosystem service and whether ecosystem services are defined as the final realised benefits (beneficial ecosystem services) or are a combination of ecological processes and functions (also often referred to as ecosystem services). The most recent advancements in this field of research recognise that there are both intrinsic values and anthropogenic values associated with the nature and the natural environment. Intrinsic values are independent of human judgement. Anthropogenic values are associated with the "benefits" received from nature in so far as they support an individual's ability to achieve a "good quality of life" comprising of aesthetic pleasure, the production or consumption of a commodity or though spiritual enlightenment [76]. 
Generally, identifying "areas of importance for ecosystem services" focuses on the final ecosystem services (benefits). Costanza et al. [77] linked the value (monetary) of ecosystem services to habitats largely in the coastal zone (seagrass/algal beds, estuaries, coral reefs). The continental shelf areas and open ocean in terms of their important contributions towards broadscale ecological processes and functions were not spatially explicit. Furthering this, a preliminary global map of the marine ecosystem service values derived from mangroves and coral reefs was produced by Spalding et al. [78]. The benefits of the ecosystem services were defined as fisheries, tourism, coastal protection and carbon storage. The initial results show that at present $32 \%$ of coral reefs and 36\% of mangroves are currently in protected areas [78]. There is also considered to be large spatial variation in the extent to which different reef and mangrove areas provide these ecosystem services due to habitat condition, and natural environmental factors [81]. Additionally, the ability to realise the ecosystem service benefits from the habitats depends on socio-economic factors associated with the distribution of human populations, infrastructure and markets [78]. From a spatial perspective, the reality of applying the ecosystem services framework (focussing on the benefits) to decision making for conservation planning reveals that ecosystem services are user defined and site specific [32]. The social and economic benefits of ecosystem functioning are realised by humans in their own natural habitat, therefore MPAs identified as generating important ecosystem service benefits (e.g. recreation) are generally linked to accessible areas close to the coast. It may also be considered that defining the relative "importance" of ecosystem services favours those services that are easy to quantify and that have a market value [79].

Identifying "areas important for biodiversity" along with "areas important for ecosystem services" will support sustainable management outlined in SDG 14.2 (Table 2). The EBSA process provides a set of scientific criteria to further the process of integrated marine management through the identification of sites that support broadscale ecological functions e.g. climate and nutrient regulation. As noted, EBSAs are not part of the current MPA process and therefore their spatial area does not currently contribute to the realisation of Aichi 11 and the SDG 14 goal of $10 \%$ spatial protection. There is complementarity between EBSA criteria and the CBD criteria for ecological representivity [80]. The scope for EBSAs features to be managed using a variety of means (CBD Decision XIII/12, para. 14) to improve the status of biodiversity may lead to the conclusion that they may be considered as an "other effective area-based conservation measure" (OECM) (see Diz et al. this issue). Although OECMs are yet to be formally recognised by the CBD, there is potential for such sites, if well managed, to contribute to ecologically representative and well-connected MPA networks. The incorporation of EBSAs into the SDG process, as part of "mainstreaming marine biodiversity into the SDGs," provides an opportunity for a broader range of tools to manage marine biodiversity for both ecological and human wellbeing benefits (see Diz et al. this issue).

Identifying "areas important for ecosystem services" is applied more successfully in coastal areas where there are direct beneficiaries, e.g. food provision or recreation. In this sense, they further support SGD 14.7, which focuses on increasing the economic benefits (fisheries, aquaculture and tourism) from sustainable resource use (Table 2) and more broadly SDG 2 which aims to deliver food security. Where ecosystems have a critical role in supporting human well-being, it is recognised that there needs to be a more systematic representation of ecosystem services in protected areas planning [78]. Spalding [81] points out that "areas of greatest importance for biodiversity often lie some distance from human populations, but those of greatest importance for their ecosystem services are likely to lie close to human populations". This is perhaps over simplistic as there are systems that do not fit this model. Whilst there are areas that are of particular importance for biodiversity and ecosystem services, for example, estuaries which can be considered to be highly productive, as well as having a high value under the ecosystem service framework for activities, such as recreation and amenity value. There are also areas of high ecosystem service value, such as beaches that are valued due to their proximity to human populations and amenity but, have relatively low levels of biodiversity and ecological function. Moving towards the implementation of SDG 14, the most pressing information need is a defined metric to better understand the "importance" of a site/area for ecosystem service delivery. Additionally, there are recent advances in methods for the assessment of ecosystem service change that can support decision makers to define what types of ecosystem services should be assessed to inform policy and planning [82-85]. However, it remains a key challenge faced by countries at national or regional levels to identify these areas and integrate them into a marine planning framework.

\section{Effective and equitably managed}

It follows that once an MPA is identified and designated then there is a need to effectively manage the site to achieve the desired conservation objectives/biodiversity targets. Protected area management is typically challenging, complex, and can potentially touch upon numerous socially charged issues [86], which, if ignored or compartmentalised, can result in the failure of the protected area to meet the objectives for which it was primarily designed [87]. Indeed, research shows that because MPAs are at the interface between social and ecological systems, short-term biological gains associated with designation may be compromised unless social issues, specifically notions of equity, are addressed in the planning and management process [87-94]. Practical considerations, such as surveillance and enforcement, especially for remote and transboundary MPAs (UNEP/MAP -RAC/SPA, 2015), also present significant challenges. Woodley et al. [32] argue that effectiveness and equity are both essential parts of protected area management but they are different concepts and should be considered as separate elements.

\subsection{Effectively managed MPAs}

In recognition that setting spatial targets for protected areas is not enough to address the global decline in biodiversity, CBD Parties established the Programme of Work on Protected Areas (PoWPA) and set a global target for $30 \%$ of the world's protected areas to have the effectiveness of their management assessed by 2010 (Goal 4.2, CBD PoWPA). The subsequent CBD Aichi Targets expanded the global target of $30 \%$ to "institutionalize management effectiveness assessments to work towards assessing $60 \%$ of the total area of protected areas by 2015 using various national and regional tools and report the results into the global database on management effectiveness" (UNEP/CBD/COP/DEC/ $\mathrm{X} / 31 / 19 \mathrm{a})$. In response to this revised target, the IUCN World Commission on Protected Areas (WCPA) developed a framework to guide assessment of management effectiveness [95]. There are three central themes by which management effectiveness may be evaluated:

- design issues relating to both individual sites and protected area systems;

- adequacy and appropriateness of management systems and processes; and

- delivery of protected area objectives, including conservation values [95].

In terms of progress towards the $60 \%$ target for assessments, Coad et al. [96] demonstrated that globally $29 \%$ of the area protected (marine and terrestrial) has been assessed and 23\% of countries have reached the $60 \%$ target. However, very few MPAs were considered in this global assessment. Kemp et al. [97] undertook a global review of the performance of spatial management in relation to the site-by-site management objectives to reveal that the objectives of spatial manage- 
ment are often poorly defined and not specific. The authors concluded that:

- The objectives of spatial management need to be measureable;

- That performance assessments need to be built into the long-term management of the site rather than relying on ad-hoc opportunities; and

- Management objectives should be set and assessed at a regional scale to assess the overall performance of the system rather than a focus on isolated sites.

Regional assessments of management effectiveness have furthered the development of protocols for assessing the management effectiveness of MPAs $[35,98]$. Results of these assessments are not encouraging, pointing towards a lack of progress in the development of conservation objectives and management plans for protected areas [39,99]. Additionally, there is a lack of a formal process for reporting management effectiveness at a country scale to support regional assessments [38,39].

\subsection{Equitably managed MPAs}

It is recognised within conservation planning that humans are integral to, and can influence, ecosystem functions. This dynamic is often referred to as the social-ecological system, where the human and ecological domains interact bilaterally and at different spatio-temporal scales $[90,100-104]$. Equity, the premise that there is a fair distribution of benefits and costs between individuals and groups of people, is a subject that is rarely assessed in MPA planning even though it is recognised as having the potential to influence intended conservation outcomes [105]. In conservation planning, equity can be addressed in a number of ways; the distribution of economic benefits (money, resource rights); the impact and benefit of conservation actions across individuals and/or groups; and the process by which stakeholders are included and provided with the opportunity to be involved in planning [106]. The distribution of equity is also often considered in the policy appraisal process via a cost-benefit analysis [107].

How equity is distributed in planning and management can be relative, perceived or actual, making evaluation of equity in MPA management a significant challenge. Exactly how equity affects conservation success is an underdeveloped area of research [108]. There are examples where equity has been redistributed following an MPA designation $[109,110]$. There is also growing concern that decisions to implement management measures for MPAs are undermining existing customary and communal fisheries tenure rights in many parts of the world, stunting or ending the individuals' and communities ability to make a livelihood from small scale fishing and the associated industries [111]. Examples are given by Pedersen et al. [112] of the displacement of fishers from their traditional fishing ground by the establishment of an MPA as part of the Coral Triangle Initiative and, the sale of fishing licences issued to foreign fishing vessels in Mauritius who will target the same species as local small scale fishers leading to potential overexploitation of the resource.

Through the inclusion of the phrase to "effectively and equitably manage" protected areas, Aichi Target 11 highlights the interconnected nature of social and ecological systems and is redirecting biodiversity conservation towards the inclusion of the broader goals of sustainability that are embodied not only in SDG 14 (Table 2) but also SDG 10 to "empower and promote the social, economic and political inclusion of all, irrespective of age, sex, disability, race, ethnicity, origin, religion or economic or other status"; SDG 16 to "Develop effective, accountable and transparent institutions at all levels; and SDG 12 to "achieve the sustainable management and efficient use of natural resources" and to "develop and implement tools to monitor sustainable development impacts for sustainable tourism that creates jobs and promotes local culture and products". Evaluation of management is vital to identify learning and good practice to support improved sustainability in marine management (SDG 14.2 (Table 2)), thus potentially increasing the economic benefits outlined in SDG 14.7 (Table 2). Integrating equity into conservation planning and management will ensure that tradeoffs are identified between stakeholders and that management interventions can support the access of small-scale artisanal fishers to marine resources and markets (SDG 14.b).

The IUCN Green List of Protected and Conserved Areas currently provides the most comprehensive approach to the assessment of management effectiveness and equity in MPAs by setting a global standard for process and assessment [113]. Key challenges that need to be addressed in the alignment of effective and equitable management between Aichi Target 11 and SDG 14 include the development and takeup of management effectiveness assessments for networks of MPAs as opposed to single sites. Additionally, there is a need to define acceptable tradeoffs between equitable management and biodiversity conservation noting that the two may not be commensurate.

\section{Integrated into the wider landscapes and seascapes}

The functional integrity and health of marine ecosystems within protected areas is dependent not only on the protection provided, but also on the ecological, economic and social interactions with surrounding areas. Protected area boundaries are permeable and therefore represent an open system that should be integrated into sectoral plans and strategies (an Ecosystem Approach). This can be of particular importance for indigenous peoples, local communities and vulnerable populations, thus requiring flexibility in seascape governance approaches [114]. For coastal seascapes, marine ecosystem health is influenced by landscape condition. This is particularly relevant where runoff from land impacts water quality and the biological health of marine communities. In addition, many marine species are dependent on land for part of their lifecycle, for example, turtles nesting on beaches, fishes migrating upriver to spawn and seabirds using cliff nesting sites. Even for very large MPAs, highly mobile animals that traverse land-sea boundaries may not receive high levels of protection because some critical habitats on land exist outside of the administrative jurisdiction of the protected area regulations [115]. In many cases, the patterns and processes occurring outside the MPAs have far greater effects on protected resources than activities within the MPAs (Cicin-Sain \& Belfiore 2005). Not considering the broader context for an MPA network within the wider seascape could result in sub-optimal conservation outcomes. For example, displacement of human activities from protected areas should be anticipated and managed because of potential increased impacts to areas of commercial and conservation importance outside of the protected area network. Yet, typically the management of MPAs has taken place within the context of a larger ocean governance system, but often with little or no integration with it (Cicin-Sain \& Belfiore 2005).

Marine Spatial Planning (MSP) has been defined by UNESCO as "a public process of analysing and allocating the spatial and temporal distribution of human activities in marine areas to achieve ecological, economic and social objectives" [116]. Furthermore, the CBD Secretariat recognises MSP as "an area-based management framework that addresses multiple management objectives. It is not a single tool, but rather an approach or framework to provide a means for improving decision making as it relates to the use of marine resources and space" [117]. MSP enables the integration of key aspects of Ecosystem Based Management (EBM) in area based planning and management to address spatial and temporal resource use and the interactive and cumulative effects arising from multiple human uses and stressors. There have been a number of large and small scale processes to progress MSP, these are reviewed in "Marine Spatial Planning in the Context of the Convention on Biological Diversity" [117].

A marine spatial plan can be designed to optimize and boost performance of an MPA network through consideration of complementary space use regulations through zoning [10]. Within the planning 
area, the creation of buffer zones around vulnerable MPAs and the design of compatible zoning for areas outside of MPAs, such as recognising blue corridors (well-connected), to provide positive synergy with MPAs, may ensure returns on investments in MPA networks. Furthermore, a broader perspective of MPAs nested within a marine spatial plan can increase ecological representativeness through protection of important areas not selected as sites for MPAs, including high human impact areas considered too threatened for the establishment of an MPA. MSP can also enable the integration of management measures for the sustainable use of marine resources and stakeholder involvement [118]. Therefore, providing an operational framework for MSP can support both biodiversity and the sustainable development objectives that are the cross-cutting themes of SDG 14 (Table 2) and potentially SDG 17: Revitalise the global partnership for sustainable development where specific emphasis is placed upon multi stakeholder partnerships which build upon "the principles and values, a shared vision, and shared goals that place people and the planet at the centre".

In terms of challenges it is noted that there is a high degree of complexity of information needs to advance MSP [119], particularly to support decision making when the integration of nature conservation into the spatial planning process is a key objective [120,121]. It has also been noted that many Marine Spatial Plans that aim to integrate the different user priorities and biodiversity into a holistic plan fail to provide processes for monitoring, reporting and review [122]. This is a major shortcoming and a key challenge for the integration into SGD 14.

\section{Conclusion}

The qualitative aspects of Aichi Target 11 are noteworthy as they shift the emphasis of "traditional" quantitative spatial habitat and species-based conservation measures towards the wider consideration of the relationship between the protection of biodiversity and human wellbeing. SDG 14 confirms the $10 \%$ protected area spatial target from Aichi target 11 and goes further by placing greater emphasis on the economic and social context of conservation measures though a series of sub-targets that aim to support economic development, environmental sustainability and social inclusion. Within SDG 14 there is, however, no detail as to how the goal may be achieved beyond the $10 \%$ protected areas target. This lack of ambition within the language of SDG14 is notable as, despite great achievements in increasing the spatial extent of MPAs it is well recorded that there is persistent degradation and loss of marine species and populations, which has the potential to critically impair the ability of marine systems to continue to provide ecosystem services that underpin human wellbeing. There is a high level of functional and spatial connectivity within marine ecosystems. It is considered that policy led by area-based targets alone will not be adequate to safeguard the important ecosystem processes and services that marine ecosystems underpin. Similarly, representativity is a key requirement to address gaps in biogeographic coverage to protect the full range of marine ecosystems.

There is obvious alignment between SDG 14 and Aichi Target 11 in so far that the principals of "sustainability" and "economic benefits" embedded in SDG 14 can be strengthened by the qualitative aspects of Aichi Target 11. Through the identification of "areas important for biodiversity and ecosystem services" sustainability is supported by the incorporation of areas that support broadscale ecological function (e.g. productivity) and areas where the ecosystem services are realised (e.g. food). Through the incorporation of the principals that have been developed under Aichi Target 11 to build resistance and resilience into protected areas networks by being "well-connected", "ecologically representative" and "integrated into the seascapes", the risks associated with multiple stressors on the marine environment that may impact upon sustainability are mitigated for and potentially reduced. By including metrics to evaluate whether a protected area is "effective and equitably managed" it is possible to identify learning and good practice to support improved sustainability in marine management.
Through the integration of "protected areas into wider landscapes and seascapes" the wider sectoral interests (along with their legal frameworks) can be taken into account to plan for a seascape that supports both biodiversity conservation and sustainable development. Perhaps aiming ultimately for $100 \%$ of the oceans to be "well managed"? It must therefore be considered that the integration of Aichi target 11 into SDG 14 can strengthen global efforts for marine biodiversity conservation which, in turn, strengthens process towards the wider principles for sustainable development and the 17 SDGs to "transform our world".

\section{Acknowledgements}

The authors would like to thank the participants of the Expert meeting to share experiences and lessons learned on achieving qualitative elements of Aichi Target 11 in marine and coastal areas, convened by the Secretariat of the Convention on Biological Diversity and the Secretariat of the Global Ocean Biodiversity Initiative (Berlin, 24-26 February 2016) whose ideas and discussions informed this paper. This work was funded via GOBI with 'in-kind' support from the authors institutions.

\section{References}

[1] CBD. Convention on Biological Diversity, United Nations, 1992.

[2] HD Jonas, S Lucas, Woking paper: Legal Aspects of Aichi Biodiveristy Target 11: A Scoping Study, Vesion 1.0., International Development Law Organisation, 2011, p. 23.

[3] Marine Conservation Institute, MPAtlas [On-line]. Available at 〈www.mpatlas. org $>$, Seattle, WA2016.

[4] D. Juffe-Bignoli, N.D. Burgess, H. Bingham, E.M.S. Belle, M.G. de Lima, M. Deguignet, et al., Protected Planet Report, UNEP-WCMC, Cambridge, UK, 2014, p. 80.

[5] G., P. Borrini-Feyerabend, T. Bueno, B. Hay-Edie, A. Lang, A. Rastogi, T. Sandwith, A primer on governance for protected and conserved areas, Stream on Enhancing Diversity and Quality of Governance, IUCN World Parks Congress, Gland, Switzerland, 2014 (IUCN).

[6] H. Jonas, K. MacKinnon, Advancing guidance on other effective area-based conservation measures: report in: Proceedings of the Second Meeting of the IUCNWCPA Task Force on Other Effective Area-based Conservation Measures, Bonn: Bundesamt für Naturschutz, 2016.

[7] NRC, Marine Protected Areas: Tools for Sustaining Ocean Ecosystems, National Academy Press, Washington DC2001. p. 272.

[8] T. Agardy, P. Bridgewater, M.P. Crosby, J. Day, P.K. Dayton, R. Kenchington, et al., Dangerous targets? Unresolved issues and ideological clashes around marine protected areas, Aquat. Conserv.: Mar. Freshw. Ecosyst. 13 (2003) 353-367.

[9] M.H. Carr, J.E. Neigel, J.A. Estes, S. Andelman, R.R. Warner, J.L. Largier, Comparing marine and terrestrial ecosystems: implications for the design of coastal marine reserves, Ecol. Appl. 13 (2003) 90-107.

[10] T. Agardy, G.N. di Sciara, P. Christie, Mind the gap: addressing the shortcomings of marine protected areas through large scale marine spatial planning, Mar. Policy 35 (2011) 226-232.

[11] D. Spalding M, I. Meliane, J. Bennett N, P. Dearden, G. Patil P, D. Brumbaugh R, Building towards the marine conservation end-game: consolidating the role of MPAs in a future ocean, Aquat. Conserv.: Mar. Freshw. Ecosyst. 26 (2016) 185-199.

[12] C.R. Margules, R.L. Pressey, Systematic conservation planning, Nature 405 (2000) $243-253$.

[13] D.D.A. Laffoley, S. Brockington, P.M. Gililand, Developing the Concepts of Good Environmental Status and Marine Ecosystem Objectives: Some Important Considerations, No 689 English Nature Research Reports, Peterborough, UK, 2006, p. 38.

[14] J.A. Ardron, The challenge of assessing whether the OSPAR network of marine protected areas is ecologically coherent, Hydrobiologia 606 (2008) 45-53.

[15] OSPAR, Guidance on Developing an Ecologically Coherent Network of OSPAR Marine Protected Areas, OSPAR Commission, London, UK, 2006. p. 11.

[16] United Nations, Draft outcome document of the United Nations summit for the adoption of the post-2015 development agenda. Draft resolution submitted by the President of the General Assembly, Sixty-ninth session, Agenda items 13 (a) and 115, A/69/L.85, New York, UN, August 12, 2015.

[17] J.D. Sachs, From millennium development goals to sustainable development goals, Lancet 379 (2012) 2206-2211.

[18] M. Spalding, L. Zeitlin-Hale, Marine protected areas: past,present and future - a global perspective, CSIRO PUBLISHING, 2016.

[19] P.J.S. Jones, E.M. De Santo, Viewpoint - Is the race for remote, very large marine protected areas (VLMPAs) taking us down the wrong track? Mar. Policy 73 (2016) 231-234.

[20] J. Lubchenco, K. Grorud-Colvert, Making waves: the science and politics of ocean protection, Science 350 (2015) 382-383.

[21] F.S. Chapin III, E.S. Zavaleta, V.T. Eviner, R.L. Naylor, P.M. Vitousek, 
H.L. Reynolds, et al., Consequences of changing biodiversity, Nature 405 (2000) 234-242.

22] D.U. Hooper, F.S. Chapin, J.J. Ewel, A. Hector, P. Inchausti, S. Lavorel, et al,, Effects of Biodiversity on Ecosystem Functioning: a consensus of current knowledge, Ecol. Monogr. 75 (2005) 3-35.

[23] Millennium Ecosystem Assessment,Ecosystems and human well-being: Synthesis. The Millennium Ecosystem Assessment series, World Resources Institute, Washington, D.C., 2005. p. 155.

[24] UNEP, Marine and coastal ecosystems and human well-being: A synthesis report based on the findings of the Millennium Ecosystem Assessment, UNEP, 2006 p. 76.

[25] B. Worm, E.B. Barbier, N. Beaumont, J.E. Duffy, C. Folke, B.S. Halpern, et al, Impacts of biodiversity loss on ocean ecosystem services, Science 314 (2006) 787-790.

[26] B.S. Halpern, S. Walbridge, K.A. Selkoe, C.V. Kappel, F. Micheli, C. D'Agrosa, et al., A Global Map of human impact on marine ecosystems, Science 319 (2008) 948-952.

[27] C.M. Roberts, G. Branch, R.H. Bustamante, J.C. Castilla, J. Dugan, B.S. Halpern, et al., Application of ecological criteria in selecting marine reserves and developing reserve networks, Ecol. Appl. 13 (2003) S215-S228.

[28] UNEP-WCMC, National and Regional Networks of Marine Protected Areas: A Review of Progress, UNEP-WCMC, Cambridge, UK, 2008, p. 156.

[29] HELCOM, Towards an ecologically coherent network of well-managed Marine Protected Areas - Implementation report on the status and ecological coherence of the HELCOM BSPA network. Baltic Sea Environmental Proceedings No. 124B, 2010, p. 148.

[30] C. Rondinini, Meeting the MPA network design principles of representation and adequacy: developing species-area curves for habitats, JNCC Report No. 439, 2010, p. 1-45.

[31] E.L. Jackson, K. Hiscock, J.L. Evans, B. Seeley, D.B. Lear, Investigating the existing coverage and subsequent gaps in protection and providing guidance on representativity and replication for a coherent network of Marine Protected Areas in England's territorial waters, Marine Life Information Network (MarLIN), Marine Biological Association of the UK. Natural England Commissioned Reports, Number 018, Plymouth, 2008, p. 1-138.

[32] S. Woodley, B. Bertzky, N. Crawhall, N. Dudley, J.M. Londoño, K. MacKinnon, et al., Meeting AICHI target 11: what does success look like for protected area systems? PARKS 18 (2012) 23-34.

[33] S. Jessen, L. Morgan, J. Bezaury-Creel, Dare to be Deep: seastates Report on North America's Marine Protected Areas (MPAs). Ottawa, Seattle, and México City: canadian Parks and Wilderness Society, Marine Conservation Institute, 2016, p. 52 .

[34] L. Lieberknecht, T. Mullier, J. Ardron. Assessment of the Ecological Coherence of the UK's Marine Protected Area Network. A Report Prepared for the Joint Links, 2014.

[35] N.L. Foster, M. Sciberras, E. Jackson, B. Ponge, V. Toison, S. Carrier, et al. Assessing the ecological coherence of the channel MPA network. Report Prepared by the Marine Institute for the Protected Area Network Across the Channel Ecosystem (PANACHE) Project. INTERREG Programme France (Channel) England Funded Project, 2014, p. 156.

[36] S. Barnard, D. Burdon, J. Strong, J. Atkins, The Ecological Coherence and Economic \& Social Benefits of the Northern Ireland MPA Network, Hull, UK, 2014.

[37] S. Rees, N. Foster, O. Langmead, C. Griffiths, Assessment of the Ecological Coherence of the MPA Network in the Celtic Seas: A report for WWF-UK by the Marine Institute, Plymouth University and The Marine Biological Association of the United Kingdom, 2015, p. 120.

[38] N.L. Foster, S.E. Rees, O. Langmead, C. Griffiths, M.J. Attrill, Ecological Coherence of an MPA network in the Celtic Seas: An MSFD Sub Region Case Study Ecological Applications, 2017, (in press)

[39] OSPAR, An Assessment of the Ecological Coherence of the OSPAR Network of Marine Protected Areas in 2012, OSPAR Commission, London, UK, 2013, p. 76.

[40] D. Johnson, J. Ardron, D. Billett, T. Hooper, T. Mullier, P. Chaniotis, et al., When is a marine protected area network ecologically coherent? A case study from the North-east Atlantic, Aquat. Conserv.: Mar. Freshw. Ecosyst. 24 (2014) 44-58.

[41] H. Piekäinen, S. Korpinen, Towards Assessment of Ecology Coherence of Marine Protected Areas Network in the Baltic Sea Region, 2008

[42] J.L. Evans, F. Peckett, K.L. Howell, Combined application of biophysical habitat mapping and systematic conservation planning to assess efficiency and representativeness of the existing High Seas MPA network in the Northeast Atlantic, ICES J. Mar. Sci.: J. du Cons. (2015).

[43] L. Fernandes, J. Day, B. Kerrigan, D. Breen, G. De'ath, B. Mapstone, et al., A process to design a network of marine no-take areas: lessons from the Great Barrier Reef, Ocean Coast. Manag. 52 (2009) 439-447.

[44] M.D. Spalding, H.E. Fox, B.S. Halpern, M.A. McManus, J. Molnar, G.R. Allen, et al., Marine ecoregions of the world: a bioregionalization of coastal and shelf areas, BioScience 57 (2007) 573-583.

[45] M.D. Spalding, V.N. Agostini, J. Rice, S.M. Grant, Pelagic provinces of the world: a biogeographic classification of the world's surface pelagic waters, Ocean Coast. Manag. 60 (2012) 19-30.

[46] S.H.M. Butchart, M. Clarke, R.J. Smith, R.E. Sykes, J.P.W. Scharlemann, M. Harfoot, et al. Shortfalls and Solutions for Meeting National and Global Conservation Area Targets. Conservation Letters, 8, 2015, 329-337.

[47] OSPAR, Background Document to Support the Assessment of Whether the OSPAR Network of Marine Protected Areas is ecologically coherent, OSPAR Commission, London, UK, 2007.

[48] OSPAR, A matrix approach to assessing the ecological coherence of the OSPAR MPA network. OSPAR Convention for the Protection of the Marine Environment of the North-East Atlantic: Meeting of the Working Group on Marine Protected Areas Species and Habitats (MASH), 2008. p. 1-15.

[49] S. Rees, N. Foster, O. Langmead, C. Griffiths, Assessment of the ecological coherence of the MPA network in the Celtic Seas: a report for WWF-UK by the Marine Institute, Plymouth University and The Marine Biological Association of the United Kingdom, 2015, p. 167.

[50] T. Stevens, Rigor and representativeness in marine protected area design, Coast. Manag. 30 (2002) 237-248.

[51] C.M. Roberts, G. Branch, R.H. Bustamante, J.C. Castilla, J. Dugan, B.S. Halpern, et al., Application of ecological criteria in selecting marine reserves and developing reserve networks, Ecol. Appl. 13 (2003) S215-S228.

[52] S. Airamé, J.E. Dugan, K.D. Lafferty, H. Leslie, D.A. McArdle, R.R. Warner, Applying ecological criteria to marine reserve design: a case study from the california channel islands, Ecol. Appl. 13 (2003) 170-184.

[53] L. Crowder, E. Norse, Essential ecological insights for marine ecosystem-based management and marine spatial planning, Mar. Policy 32 (2008) 772-778.

[54] C. Folke, S. Carpenter, B. Walker, M. Scheffer, T. Elmqvist, L. Gunderson, et al., Regime shifts, resilience, and biodiversity in ecosystem management, Annu. Rev. Ecol., Evol., Syst. 35 (2004) 557-581.

[55] T.D. O'Hara, A.A. Rowden, N.J. Bax, A Southern Hemisphere Bathyal fauna is distributed in latitudinal bands, Curr. Biol. 21 (2011) 226-230.

[56] S.R. Palumbi, Population genetics, demographic connectivity, and the design of marine reserves, Ecol. Appl. 13 (2003) 146-158.

[57] J. Kool, A. Moilanen, E. Treml, Population connectivity: recent advances and new perspectives, Landsc. Ecol. 28 (2013) 165-185.

[58] A.D. Olds, R.M. Connolly, K.A. Pitt, S.J. Pittman, P.S. Maxwell, C.M. Huijbers, et al., Quantifying the conservation value of seascape connectivity: a global synthesis, Glob. Ecol. Biogeogr. 25 (2016) 3-15.

[59] G.P. Jones, G.R. Russ, P.F. Sale, R.S. Steneck, Theme section on "Larval connectivity, resilience and the future of coral reefs", Coral Reefs 28 (2009) 303-305.

[60] J.P. Kritzer, P.F. Sale, Metapopulation ecology in the sea: from Levins' model to marine ecology and fisheries science, Fish. Fish. 5 (2004) 131-140.

[61] S.J. Pittman, C.A. McAlpine, Movements of marine fish and decapod crustaceans: process, theory and application, in: A.J. Southward PATCMY, L.A. Fuiman (Eds.), Advances in Marine Biology, Academic Press, 2003, pp. 205-294.

[62] R.A. Magris, E.A. Treml, R.L. Pressey, R. Weeks, Integrating multiple species connectivity and habitat quality into conservation planning for coral reefs, Ecography (2015) (n/a-n/a).

[63] S.J. Pittman, M.E. Monaco, A.M. Friedlander, B. Legare, R.S. Nemeth, M.S. Kendall, et al., Fish with chips: tracking reef fish movements to evaluate size and connectivity of caribbean marine protected areas, PLoS One. 9 (2014) e96028.

[64] A. Grüss, D.M. Kaplan, S. Guénette, C.M. Roberts, L.W. Botsford, Consequences of adult and juvenile movement for marine protected areas, Biol. Conserv. 144 (2011) 692-702.

[65] E.M. Olsen, D. Johnson, P. Waever, R. Goni, M.C. Ribeiro, M. Rabaut, et al, Achieving ecologically coherent MPA networks in Europe: science needs and priorities, in: K.E. Larkin, N. McDonough (Eds.), Marine Board Position, European Marine Board, Ostend, Belgium, 2013, pp. 1-88.

[66] L.J. McCook, G.R. Almany, M.L. Berumen, J.C. Day, A.L. Green, G.P. Jones, et al., Management under uncertainty: guide-lines for incorporating connectivity into the protection of coral reefs, Coral Reefs 28 (2009) 353-366.

[67] A.L. Green, A.P. Maypa, G.R. Almany, K.L. Rhodes, R. Weeks, R.A. Abesamis, et al, Larval dispersal and movement patterns of coral reef fishes, and implications for marine reserve network design, Biol. Rev. 90 (2015) 1215-1247.

[68] United Nations, Convention on Biological Diversity, 1992:28.

[69] R. Costanza, R. d'Arge, R. de Groot, S. Farber, M. Grasso, B. Hannon, et al., The value of the world's ecosystem services and natural capital, Ecol. Econ. 25 (1998) 3-15.

[70] Defra. An introductory guide to valuing ecosystem services, Department for Environment, Food and Rural Affairs; 2007.

[71] A. Balmford, A.S.L. Rodrigues, M. Walpole, P. ten Brink, M. Kettunen, L. Braat, et al. The economics of biodiversity and ecosystems: scoping the science. Cambridge, UK (contract: ENV/070307/2007/486089/ETU/B2), 2008.

[72] M.B. Potschin, R.H. Haines-Young, Ecosystem services: exploring a geographical perspective, Progress. Phys. Geogr. 35 (2011) 575-594.

[73] D.C. Dunn, J. Ardron, N. Bax, P. Bernal, J. Cleary, I. Cresswell, et al., The Convention on Biological Diversity's Ecologically or Biologically Significant Areas: origins, development, and current status, Mar. Policy 49 (2014) 137-145.

[74] P. Weaver, D. Johnson, Biodiversity: think for marine conservation, Nature 483 (2012) 399.

[75] TEEB, P. Kumar (Ed.), The Economics of Ecosystems and Biodiversity: The Ecological and Economic Foundations, UNEP, London, Washington DC, 2010, p. 411.

[76] S. Díaz, S. Demissew, J. Carabias, C. Joly, M. Lonsdale, N. Ash, et al., The IPBES Conceptual framework - connecting nature and people, Curr. Opin. Environ. Sustain. 14 (2015) 1-16.

[77] R. Costanza, R. d'Arge, R. de Groot, S. Farber, M. Grasso, B. Hannon, et al., The value of the world's ecosystem services and natural capital, Nature 387 (1997) 253-260.

[78] M. Spalding, L. Burke, J.R. Hutchison, Ermgassen Pz, H. Thomas, J. Ashpole, et al., Attaining Aichi Target 11: How well are marine ecosystem services covered by protected areas? Discussion Paper prepared for the World Parks Congress, The Nature Conservancy, University of Cambridge, UNEP, WCMC, Sydney, 2014, p. 7.

[79] J.G. Robinson, Ethical pluralism, pragmatism, and sustainability in conservation practice, Biol. Conserv. 144 (2011) 958-965. 
[80] D. Diz, Unravelling the Intricacies of Marine Biodiversity Conservation and its Sustainable Use: An Overview of Global Frameworks and Applicable Concepts Edinburgh School of Law Research Paper No 2016/11 Available at SSRN: 〈https:// ssrncom/abstract $=2764502>, 2016$.

[81] M. Spalding, I. Meliane, A. Milam, C. Fitzgerald, L. Hale, Protecting Marine Spaces: global Targets and Changing Approaches, Ocean Yearbook 27 (2013), pp. 213-248.

[82] E.L. Jackson, S.E. Rees, C. Wilding, M.J. Attrill, Use of a seagrass residency index to apportion commercial fishery landing values and recreation fisheries expenditure to seagrass habitat service, Conserv. Biol. 29 (2015) 899-909.

[83] K.K. Arkema, G.M. Verutes, S.A. Wood, C. Clarke-Samuels, S. Rosado, M. Canto, et al., Embedding ecosystem services in coastal planning leads to better outcomes for people and nature, in: Proceedings of the National Academy of Sciences, 112, 2015, 7390-7395.

[84] L. Pendleton, R. Mongruel, N. Beaumont, T. Hooper, M. Charles, A triage approach to improve the relevance of marine ecosystem services assessments, Mar. Ecol. Progress. Ser. 530 (2015) 183-193.

[85] T. Potts, D. Burdon, E. Jackson, J. Atkins, J. Saunders, E. Hastings, et al., Do marine protected areas deliver flows of ecosystem services to support human welfare? Mar. Policy 44 (2014) 139-148.

[86] M.B. Mascia, C.A. Claus, R. Naidoo, Impacts of marine protected areas on fishing communities, Conserv. Biol. 24 (2010) 1424-1429.

[87] P. Christie, Marine Protected Areas as Biological Successes and Social Failures in South East Asia, 42 American Fisheries Society Symposium, 2004, pp. 155-164.

[88] P. Christie, B.J. McCay, M.L. Miller, C. Lowe, A.T. White, R. Stoffle, et al., Toward developing a complete understanding: a social Science research agenda for marine protected areas, Fisheries (2003) 28.

[89] C.J. Klein, A. Chan, L. Kircher, A.J. Cundiff, N. Gardner, Y. Hrovat, et al., Striking a balance between biodiversity conservation and socioeconomic viability in the design of marine protected areas, Conserv. Biol. 00022 (2008) 691-701.

[90] R. Pollnac, P. Christie, J. Cinner, T. Dalton, T. Daw, G. Forrester, et al., Marine reserves as linked social-ecological systems, Proc. Natl. Acad. Sci. Usa. 107 (2010) $18262-18265$

[91] S. Rosendo, K. Brown, A. Joubert, N. Jiddawi, M. Mechisso, A clash of values and approaches: a case study of marine protected area planning in Mozambique, Ocean Coast. Manag. 54 (2011) 55-65.

[92] K. Leleu, F. Alban, D. Pelletier, E. Charbonnel, Y. Letourneur, C.F. Boudouresque, Fishers' perceptions as indicators of the performance of Marine Protected Areas (MPAs), Mar. Policy 36 (2012) 414-422.

[93] E.A. Norse, Ecosystem-based spatial planning and management of marine fisheries: why and how? Bull. Mar. Sci. 86 (2010) 179-195.

[94] S.E. Rees, M.J. Attrill, M.C. Austen, S.C. Mangi, L.D. Rodwell, A thematic costbenefit analysis of a marine protected area, J. Environ. Manag. 114 (2013) 476-485.

[95] M. Hockings, S. Stolton, F. Leverington, N. Dudley, J. Courrau, P. Valentine (Ed.), Evaluating Effectiveness: A framework for assessing management effectiveness of protected areas, 2nd edition, IUCN, Gland, Switzerland and Cambridge, UK, 2006, p. 121.

[96] L. Coad, F. Leverington, N.D. Burgess, I.C. Cuadros, J. Geldmann, T.R. Marthews, et al., Progress Towards the CBD Protected Area Management Effectiveness Targets, PARKS, 2013, p. 19.

[97] J. Kemp, G.P. Jenkins, D.C. Smith, E. Fulton, Measuring the performance of spatial management in marine protected areas, Oceanography and Marine Biology, CRC Press, 2012, pp. 287-314.

[98] OSPAR, Guidelines for the management of marine protected areas in the OSPAR maritime area. Reference number: 2003-18, OSPAR Convention for the Protection of the Marine Environment of the North-east Atlantic, 2003.

[99] D. Rodríguez-Rodríguez, J. Rodríguez, D. Abdul Malak, Development and testing of a new framework for rapidly assessing legal and managerial protection afforded by marine protected areas: mediterranean Sea case study, J. Environ. Manag. 167 (2016) 29-37.

[100] P.R. Armsworth, K.M.A. Chan, G.C. Daily, P.R. Ehrlich, C. Kremen, T.H. Ricketts, et al., Ecosystem-service science and the way forward for conservation, Conserv. Biol. 21 (2007) 1383-1384.
[101] R. Curtin, R. Prellezo, Understanding marine ecosystem based management: a literature review, Mar. Policy 34 (2010) 821-830.

[102] F. Berkes, J. Colding, C. Folke, Navigating Social-ecological Systems: Building Resilience for Complexity and Change, Cambridge University Press, Cambridge, UK, 2003.

[103] J. Liu, T. Dietz, S.R. Carpenter, M. Alberti, C. Folke, E. Moran, et al., Complexity of coupled human and natural systems, Science 317 (2007) 1513-1516.

[104] E. Ostrom, A general framework for analyzing sustainability of social-ecological systems, Science 325 (2009) 419-422.

[105] H. Tallis, S. Polasky, J.S. Lozano, S. Wolny, Inclusive wealth accounting for regulating ecosystem services, Inclusive Wealth Report 2012, Measuring Progress toward Sustainability, Cambridge, UK, 2012.

[106] B.S. Halpern, C.J. Klein, C.J. Brown, M. Beger, H.S. Grantham, S Mangubhai, et al. Achieving the triple bottom line in the face of inherent trade-offs among social equity, economic return, and conservation, Proceedings of the National Academy of Sciences, 2013, 110, 6229-6234.

[107] S. Fletcher, S. Rees, Marine conservation zone impact assessment review, A report for The wildlife Trusts by the Centre for Marine and Coastal Policy Research, Plymouth University, 2015, 31.

[108] C. Klein, M.C. McKinnon, B.T. Wright, H.P. Possingham, B.S. Halpern, Socia equity and the probability of success of biodiversity conservation, Glob. Environ. Change 35 (2015) 299-306.

[109] S.E. Rees, L.D. Rodwell, M.J. Attrill, M.C. Austen, S.C. Mangi, The value of marine biodiversity to the leisure and recreation industry and its application to marine spatial planning, Mar. Policy 34 (2010) 868-875.

[110] S.C. Mangi, L.D. Rodwell, C. Hattam, Assessing the impacts of establishing MPAs on fishermen and fish merchants, 40 The Case of Lyme Bay, UK. Ambio, 2011, pp. 457-468.

[111] N.J. Bennett, H. Govan, T. Satterfield, Ocean grabbing, Mar. Policy 57 (2015) 61-68.

[112] C., T. Feodoroff, R. Reuter, J. Franco, N. Buxton, M.C. Barbesgaard, The globa ocean grab: a primer Transnational Institute, Masifundise, Afrika Kontakt and World Forum of Fisher Peoples, Amsterdam, The Netherlands, 2014.

[113] International Union for the Conservation of Nature, Green List, International Union for Conservation of Nature; 2016.

[114] J. Day, N. Dudley, M. Hockings, G. Holmes, Dd.A. Laffoley, S. Stolton, et al., Guidelines for Applying The IUCN Protected Area Management Categories to Marine Protected Areas, IUCN, 2012.

[115] J. Dryden, A. Grech, J. Moloney, M. Hamann, Rezoning of the Great Barrier Reef World Heritage Area: does it afford greater protection for marine turtles? Wildl. Res. 35 (2008) 477-485.

[116] C. Ehler, F. Douvere, Marine Spatial Planning: a Step-by-step Approach toward Ecosystem-based Management. Intergovernmental Oceanographic Commission and Man and the Biosphere Programme, UNESCO, Paris, 2009, p. 99 (IOC Manual and Guides No. 53, ICAM Dossier No. 6.).

[117] Secretariat of the Convention on Biological Diversity and the Scientific and Technical Advisory Panel, Marine Spatial Planning in the Context of the Convention on Biological Diversity: A study carried out in response to CBD COP 10 decision X/29. Technical Series No 68, Montreal, 2012, p. 44.

[118] E.M. De Santo, Environmental justice implications of Maritime Spatial Planning in the European Union, Mar. Policy 35 (2011) 34-38.

[119] B.S. Halpern, J. Diamond, S. Gaines, S. Gelcich, M. Gleason, S. Jennings, et al., Near-term priorities for the science, policy and practice of coastal and marine spatial planning (CMSP), Mar. Policy 36 (2012) 198-205.

[120] M.M. Foley, B.S. Halpern, F. Micheli, M.H. Armsby, M.R. Caldwell, C.M. Crain et al., Guiding ecological principles for marine spatial planning, Mar. Policy 34 (2010) 955-966.

[121] Z. Kyriazi, F. Maes, M. Rabaut, M. Vincx, S. Degraer, The integration of nature conservation into the marine spatial planning process, Mar. Policy 38 (2013) 133-139.

[122] J.S. Collie, W.L. Adamowicz, M.W. Beck, B. Craig, T.E. Essington, D. Fluharty, et al., Marine spatial planning in practice, Estuar., Coast. Shelf Sci. 117 (2013) $1-11$. 